\title{
Erratum to: Characterization of the stress-inducible $O s N C E D 3$ promoter in different transgenic rice organs and over three homozygous generations
}

\author{
Seung Woon Bang $\cdot$ Su-Hyun Park • \\ Jin Seo Jeong • Youn Shic Kim • Harin Jung • \\ Sun-Hwa Ha $\cdot$ Ju-Kon Kim
}

Published online: 1 July 2014

(c) Springer-Verlag Berlin Heidelberg 2014

Erratum to: Planta (2013) 237:211-224

DOI 10.1007/s00425-012-1764-1

Unfortunately, the electronic supplementary files have been omitted in the original publication. The electronic supplementary files are now linked with this erratum article.

The online version of the original article can be found under doi:10.1007/s00425-012-1764-1.

Electronic supplementary material The online version of this article (doi:10.1007/s00425-014-2112-4) contains supplementary material, which is available to authorized users.

S. W. Bang · S.-H. Park · J. S. Jeong · Y. S. Kim · H. Jung · J.-K. Kim $(\bowtie)$

School of Biotechnology and Environmental Engineering,

Myongji University, Yongin 449-728, Korea

e-mail: jukon306@gmail.com

S.-H. Ha $(\bowtie)$

National Academy of Agricultural Science, RDA,

Suwon 441-707, Korea

e-mail: sunhwa@korea.kr 